\title{
Geometrías.
}

\section{Pinterest como herramienta participativa para crear exposiciones digitales}

\author{
María Casas González * \\ Universidad Autónoma de Madrid. España
}

RECIBIDO: 12.09.2015 / ACEPTADO: 12.01.2016

\begin{abstract}
Resumen
Primera aproximación a Pinterest como herramienta social que permite coleccionar y compartir imágenes y, por ello, reflexionamos sobre sus características como herramienta para crear exposiciones digitales. Su uso ayudaría tanto a la difusión de la cultura como a nuestra participación en ella. Su diseño hipermedia y su interactividad serán algunos de sus aspectos determinantes.
\end{abstract}

Además hemos realizado una exposición digital dentro del marco de la Cultura Clásica Contemporánea que ha permitido estudiar la herramienta participativa para explorar las formas geométricas como una característica latente en el diseño y su proceso creativo.

Palabras clave: Pinterest, exposición, digital, hipermedia, geometría, cultura, red social.

\section{Pinterest as a participative tool to create digital exhibitions}

\begin{abstract}
First approach to Pinterest as a social network that allows to collect and share images and therefore reflect on its characteristics as a tool to produce digital exhibitions. That can make a significant contribution to the spread of the culture and social involvement. Its hypermedia design and interactivity are two of its key aspects.
\end{abstract}

Furthermore we created a digital exhibition within Contemporary Classical Culture framework which allows to prove this participative tool to explore the geometrical forms as a latent characteristic in design and its creative process.

Keywords: Pinterest, exhibition, digital, hypermedia, geometry, culture, social network.

\section{Pinterest como expositor virtual}

La idea de realizar una exposición virtual desde Pinterest nace con un interés académico (desde la asignatura Diseño, imagen corporativa e identidad visual del máster MDSCA) de realizar una colección digital participativa basada en explorar las múltiples líneas que acontecen en el marco de la Cultura Clásica Contemporánea².

La iniciativa de usar Pinterest nos animaba también a realizar un estudio de la red social (social networking) como herramienta de exposiciones digitales ${ }^{3} \mathrm{y}$, por tanto, para el desarrollo del diseño 
y de la "cultura digital", entendida como la versión digital del patrimonio cultural, cuya finalidad, al igual que cualquier institución en este ámbito es la de coleccionar, contextualizar, conservar y transmitir ${ }^{4}$. Partiendo de esto, la elección de Pinterest para realizar el estudio, y la puesta en marcha de nuestra propia exposición digital, se basa en los aspectos que más caracterizan y diferencian a esta red social del resto: su poder y fuerza visual y sus objetivos principales de coleccionar y compartir.

Vamos a resumir brevemente el origen y funcionamiento de esta red social. Nace en marzo del 2010, por lo tanto tan solo lleva funcionando 5 años. Su actividad principal es la recopilación de imágenes digitales y vídeos en tableros, que funcionan a modo de colecciones. A cada imagen Pinterest le llama pin, cada pin contiene la descripción que agrega el propio usuario y el link hacia su origen. El poder social de esta red se encuentra en que cada persona puede agregar imágenes (pin it), repinear (repin), agregar a tus gustos añadiéndole un "me gusta" (like it) o comentar la imagen. Además, se pueden seguir los tableros de la gente o directamente los perfiles de otras personas según gustos personales.

El interfaz, que constituye la parte más atractiva y visual de la plataforma, está diseñada como una red de imágenes que aparecen dispuestas a lo largo de toda la pantalla. Este diseño, así como las continuas sugerencias (con respecto a tus gustos), invita a una navegación fluida. Hall y Zarro explican que junto a la sencillez del interfaz, el éxito de Pinterest puede estar en la simplicidad y rapidez con la que un usuario puede realizar todos los procesos principales de la red social (recopilación e intercambio) ${ }^{5}$ así como su interacción con otras redes.

Pero, para que un tablón de Pinterest llegue a ser una exposición digital, hay que crear un discurso que será lo que diferenciará, como explica G.Ellis Burcaw, exhibición (display) de exposición (exhibit) $)^{6}$ y por tanto se pase de una mera exhibición de imágenes digitales a una comunicación efectiva de un discurso que parte de una determinada interpretación.

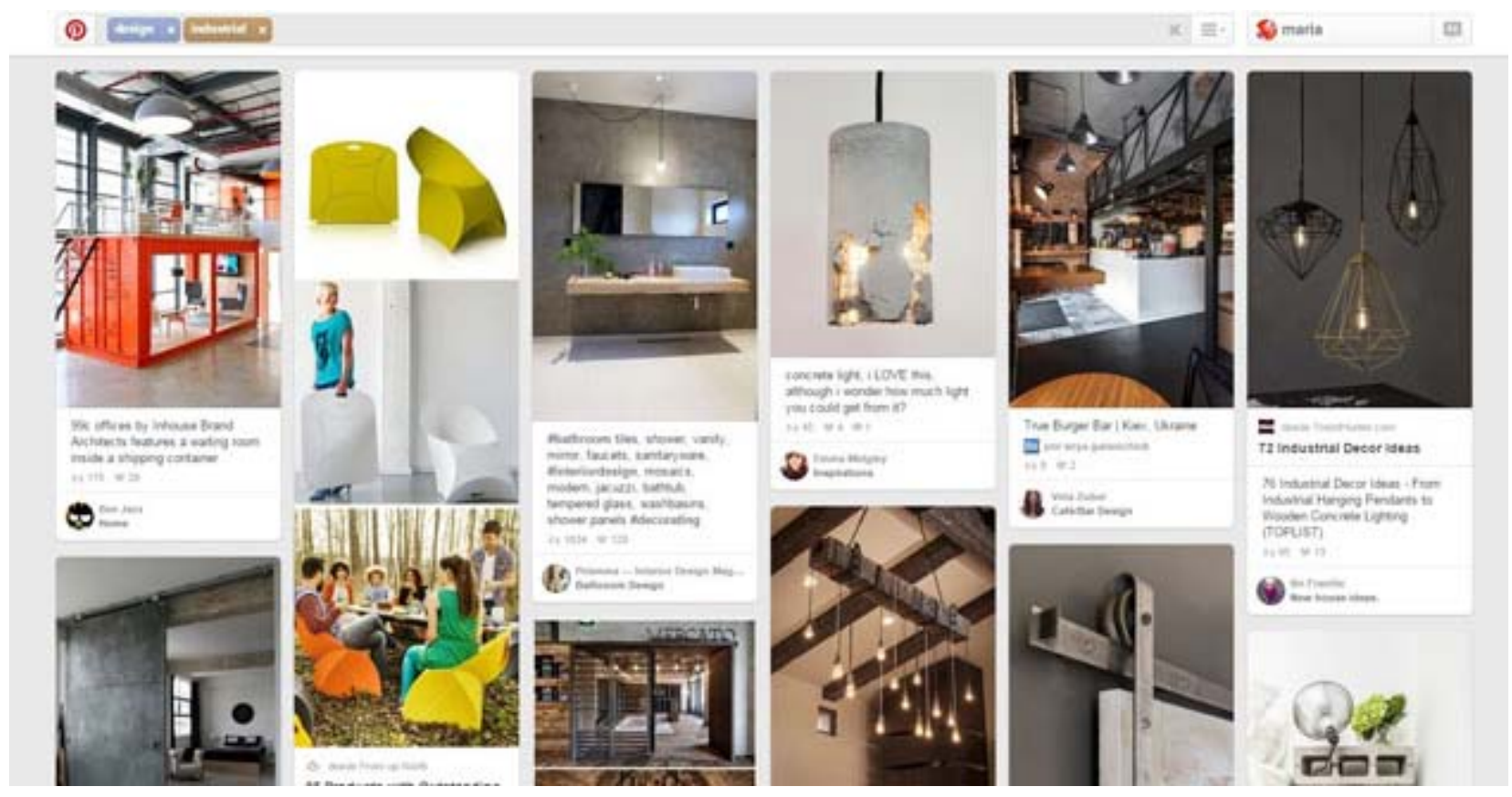

Fig. 1. Diseño de interfaz. 
Podemos ver cómo los tres aspectos fundamentales de la exposición (contenido, comunicación, presentación) van a depender de las características intrínsecas a la plataforma y su uso. A partir de aquí vamos a destacar las novedades que esta forma de 'coleccionar' obras puede aportar a la tradicional forma de exposición.

El contenido dependerá de la metodología que use el comisario para el desarrollo del proyecto expositivo y el discurso. Dentro del contenido expositivo, hay un tema muy interesante que nos aportan los nuevos medios digitales. $Y$ es que podemos ver cómo el contenido se expande, en el sentido de que ya no incluye únicamente las obras expuestas y el discurso, sino que, si entendemos Pinterest como un sitio/lugar de comisariado social (social curation site ${ }^{7}$ ), podemos además, concebir como contenido los datos y metadatos que este medio digital nos proporciona. $A$ consequence of the participatory web has been a great increase in the quantity and variety of social annotation and user-generated metadata ${ }^{8}$, lo que quiere decir que, el hecho de utilizar una herramienta que se basa en la web social 2.0, todos los repines, like[s], y comentarios que conlleva esta muestra, pasarán a formar parte de la misma y, por lo tanto, conllevará un aumento de la información y del contenido, que se podrá analizar posteriormente.

Un hecho importante que está sucediendo en las redes sociales, y que se irá potenciando cada vez más en ellas, es el enriquecimiento de estos metadatos. En especial Pinterest ha añadido metadatos que se podrán implementar, en el caso de que los pines sean de determinada temática (productos, recetas, lugares, películas y artículos), gracias a los Rich Pins ${ }^{9}$. Esperemos que posteriormente se amplíen estas tipologías de pines.

La comunicación será un factor determinante porque, el hecho de elegir una red social como Pinterest, implica que la comunicación sea plenamente visual y no dependerá ni de barreras económicas, ni de espacio, ni de tiempo. Por lo tanto se puede decir que, en términos de comunicación, también el uso de las redes sociales, como herramienta, para la creación de exposiciones, puede ampliar la divulgación de la misma dependiendo del comisario, únicamente, si se pretende limitar en el tiempo o no.

La presentación va a depender del interfaz de la plataforma, pero la forma de presentar las imágenes, así como su forma de comunicar y su interactividad, harán que las exposiciones virtuales tengan un diseño hipermedia ${ }^{10}$ que va a enriquecer la estructura semántica del discurso. El hecho de poder agregar vínculos hacia otros lugares web, o que la propia plataforma te sugiera más tablones similares, va a hacer que la navegación sea muy interactiva y tan profunda como el visitante desee.

"Las mismas [exposiciones desarrolladas en internet] ofrecen posibilidades que no siempre permiten las exposiciones tradicionales de objetos materiales (agrupamiento de objetos, nuevos modos de presentación y análisis, etc.)"11.

Con esto hemos querido contemplar las ideas que nos han parecido más interesantes a la hora de usar Pinterest como una plataforma social de base participativa, en la que se pueden exponer ciertas piezas visuales, evidenciando un posicionamiento determinado a través de un discurso. 
Si bien es cierto que las redes sociales actualmente tienen un fuerte componente económico (ecommerce), por la influencia que ejercen sobre los usuarios (consumidores en potencia) con esta iniciativa lo que pensamos poner de manifiesto es que las redes sociales, en especial Pinterest, pueden presentarse como herramientas interesantes para la creación y divulgación del conocimiento, así como potenciadoras de la capacidad de opinión reflexiva y juicio crítico de las personas que visitan y participan en estas redes.

\begin{abstract}
Se hace evidente, en las más interesantes propuestas de los nuevos comportamientos artísticos "on line", su potencial para hacer que parte de la información y datos que circulan por las redes puedan ser no sólo consumidos, sino debidamente situados en relación a sus elementos existenciales. Es decir, uno de los compromisos de la mejor creación artística en el contexto de la "Web 2.0" sería el diseñar nuevas vías para llevar el modelo de la experiencia interpretativa propia de las prácticas artísticas al campo de la interacción social y comunicativa. ${ }^{12}$
\end{abstract}

\title{
Geometrías
}

El proyecto que aquí exponemos surgió de la idea de realizar una colección participativa sobre el diseño dentro del marco de la Cultura Clásica Contemporánea ${ }^{13}$ (desde ahora CCC). La colección resultante se puede ver en el tablero Diseño CCC y fue realizada por los alumnos del máster MDSCA, anteriormente nombrado, dentro de la asignatura Diseño, imagen corporativa e identidad visual impartida por ele profesor Sebastián García Garrido. En dicha colección se pueden apreciar diversos diseños realizados en el ámbito de la CCC, que engloba España, Portugal, Italia y toda América; y cuyos principales objetos de estudio se encuentran en los sectores de producto, gráfico, arquitectura y moda.

Desde este proyecto, que pretendemos sea un proyecto abierto a nuevas iniciativas y colaboraciones, parte nuestro objetivo de analizar o por lo menos iniciarnos al estudio de la CCC. La muestra que obtuvimos está marcada por este ámbito de la CCC que "conforma un panorama especialmente rico en diversidad, creatividad y calidad, con un inmenso potencial cultural y estético"14, y propicia un acercamiento a este interesante tema. Si se observan los objetos que se añadieron a esta colección, se pueden ver gran parte de las características de este marco de la CCC como es el mestizaje, la influencia latina, diversidad cultural (marcada por el carácter local) y la tendencia humanista que destaca Sebastián García. El hecho de navegar por el tablón descubrirá sus particularidades.

La idea es que, tras de este acercamiento global y heterogéneo, surgiera un nuevo tablón inspirado en este último pero con un enfoque concreto. Para lo cual hemos realizado el tablón Geometrías https://www.pinterest.com/mcgmaria/geometrías. Partiendo de dos de los ejemplos más sugestivos a nuestro parecer, como son los pines añadidos por las compañeras Alicia Calderón y Paloma León: la botella $L H 2 O$, de Pedrita Estudios, Portugal, 2009; y el estudio para un packaging inspirado en Gaudí, EE.UU. 

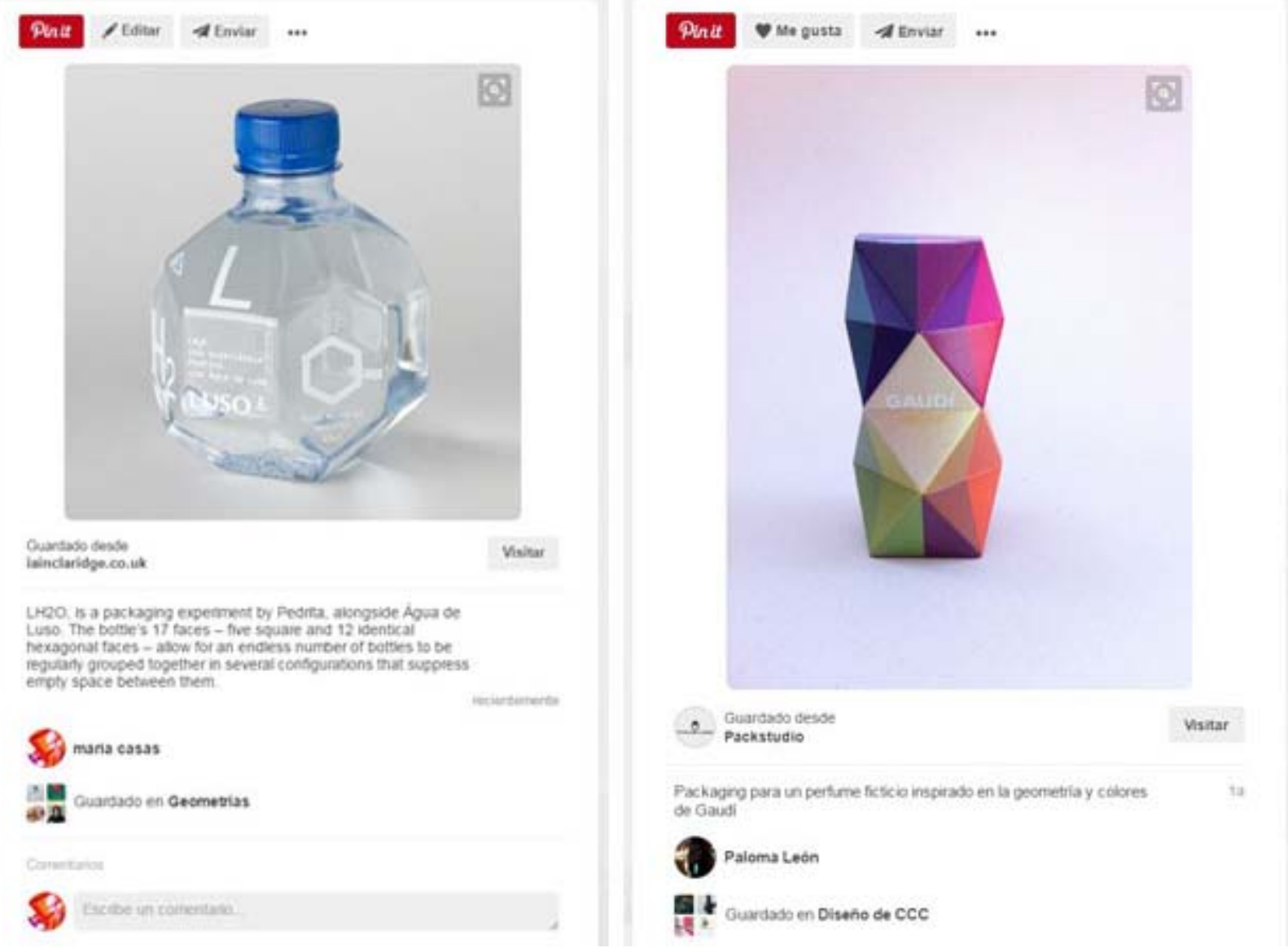

Fig. 2. Imágenes del tablón Diseño CCC.

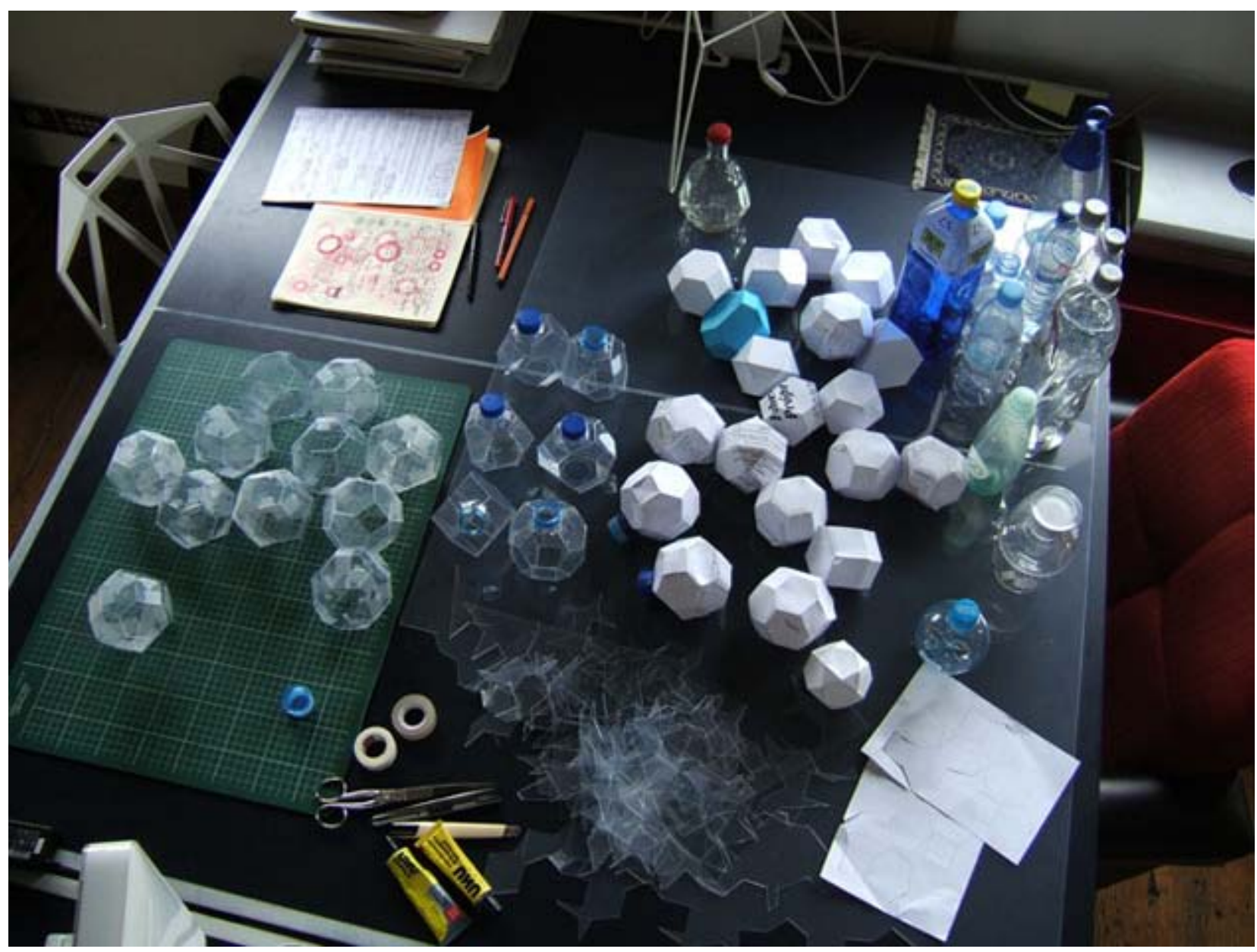

Fig. 3. LH2O, an experiment by Pedrita with Água de Luso. Proceso del proyecto investigación del diseño de LH2O Luso, 2009 en www.pedrita.net. 
Partiendo de estas imágenes y su sugerente forma poliédrica, hemos creado una nueva colección cuyo discurso se articula a partir del tema central de la geometría. Lo que pretendemos con esto no es explorar uno de tanto estilos que podemos encontrar hoy en día desarrollados desde el diseño, sino adentrarnos en la idea de la Cultura Clásica Contemporánea siguiendo esta temática concreta desde diversas lecturas.

Si en 2009 Nicolas Bourriaud, comisario de la Trienal de Arte de Londres en 2009, certifica la muerte de la posmodernidad en el arte, en el diseño se configura también un regreso de la modernidad. Esta nueva consideración del proyecto asimila los aspectos positivos que se han dado en esta última tendencia, y retoma la investigación y el sistema proyectual para buscar una estética de lo esencial. ${ }^{15}$

Esta búsqueda de lo esencial es muy importante para entender esta colección. En la mayor parte de los diseños vemos cómo los diseñadores de manera razonada han puesto mucho interés en este proceso de investigación de búsqueda de la estética adecuada al producto.

Encontramos un interés, por parte de los diseñadores, en plasmar la etapa de gestación del diseño, mostrando un claro apego por lo artesanal, por las tradiciones y, sobre todo, por mostrar estas etapas previas al objeto terminado. Creo que se aprecia aquí una clara vuelta a la modernidad, donde el proceso prima por encima del acabado final, sin menoscabo de éste.

En la época en la que vivimos, donde lo virtual y lo digital se mezclan con la realidad, creo que las páginas web de los diseñadores, así como se está demostrando, pueden llegar a ser el nuevo "taller" del artista o, por lo menos, un escaparate a ese taller. En el sentido de que no únicamente se presentan los objetos de diseño ya creados, sino que se muestra todo el proceso. Un ejemplo muy interesante lo encontramos en la página del diseñador portugués André Teoman, donde destaca, además de una cuidada estética web, la limpieza; y el orden prima por encima de todo, la idea de mostrar el proceso por el cual ha llegado al diseño definitivo.

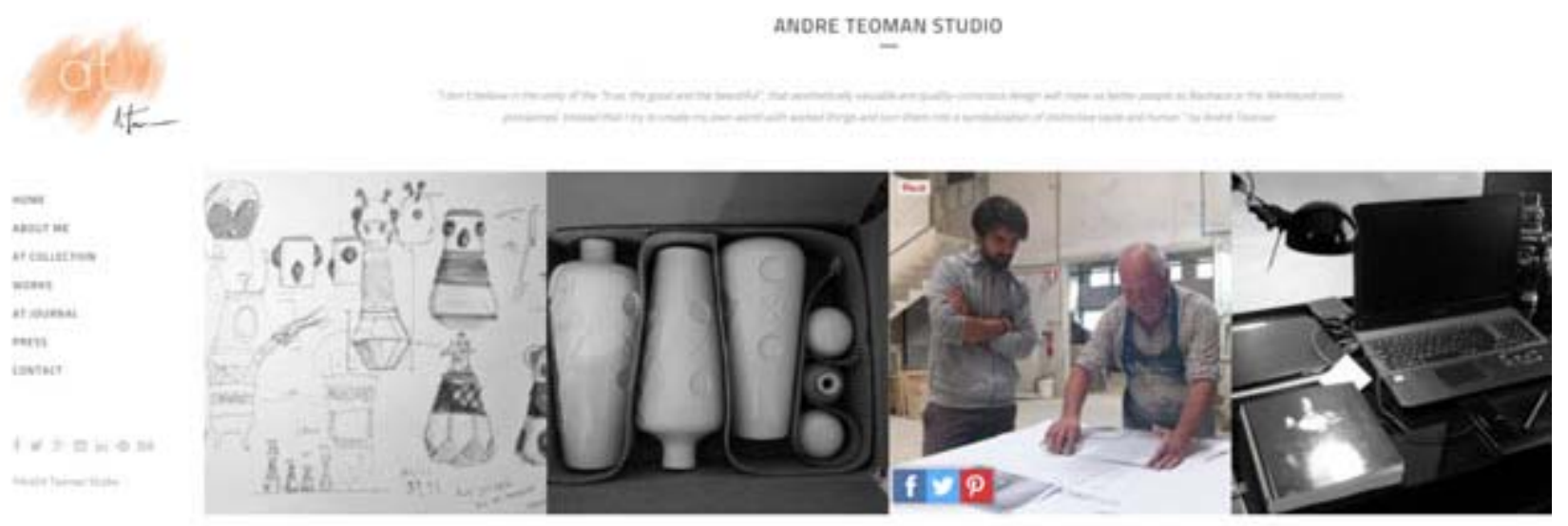

Fig. 4. Web de André Teoman Studio www.andreteoman.com.

Partiendo de esta revalorización de lo artesanal podemos articular una de las lecturas a las que anteriormente me refería, como la idea de la exploración de lo geométrico a través de lo artesanal.

Un gran ejemplo de esta exploración, que bien merecería una exposición temática, sería el ejemplo de los artistas portugueses que usan la cerámica y los azulejos. El azulejo es un referente 
tradicional usado por grandes arquitectos, como Francisco Keil do Amaral (1910-1975) y José Carlos Loureiro (1925), que colaboran junto con artistas locales como Eduardo Nery (1938-2013), usando este material como elemento de innovación y una visión contemporánea, desde la segunda mitad del siglo $\mathrm{XX}$, pero con una gran carga de manufactura ${ }^{16}$.

En particular, Eduardo Nery y su Panel de azulejos en patrón, usado en el Centro de Saúde de Mértola de 1981 sobre patrón de 1966, ejemplifica a la perfección el tipo de producción que realiza y cómo su bagaje artístico es usado para engrandecer la tradición del azulejo: "aveva creato opere con la tecnica del collage, dell'incisione, del mosaico e si era interessato alla fotografia (...) ha soggiornato a Parigi (1959), dove si è interessato alle opere di natura astratta e alla grammatica dell'Op Art, della quale è stato uno dei pionieri in Portogallo"17.

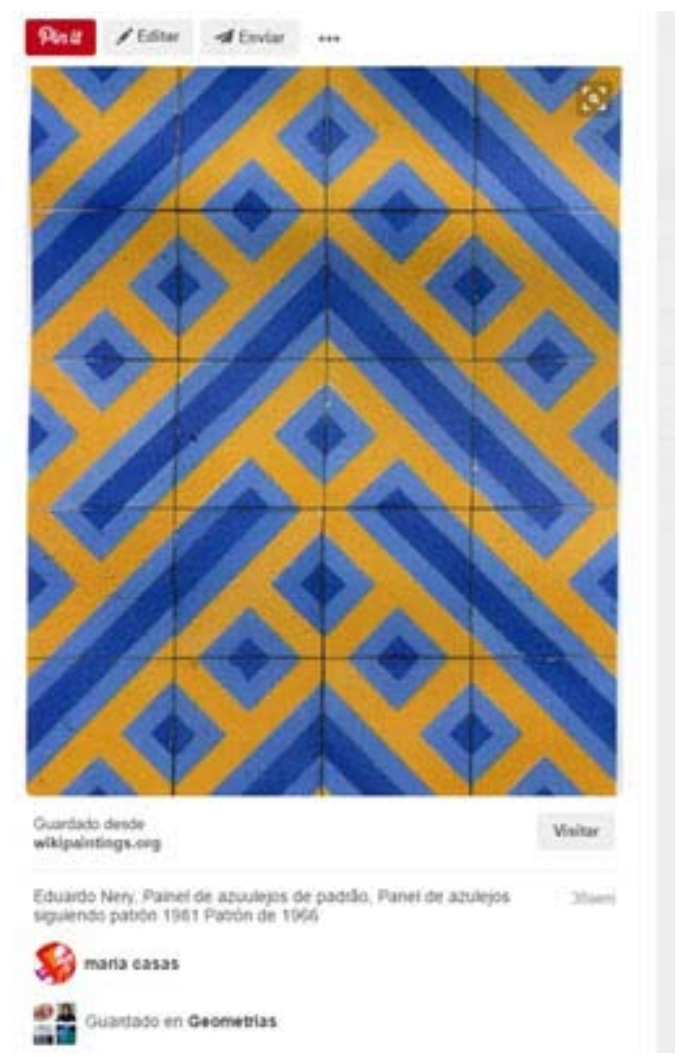

Fig. 5. Cosido del borde incorporar el backing.

Nery ha sempre sostenuto l'importanza dell'effetto visivo di geometrie, texture e colori nell'azulejaria. Egli ha affermato che quando si osserva un rivestimento in azulejos dalle grandi dimensioni e ad ampia distanza, per esempio di una facciata, si nota immediatamente una struttura, una texture, e questa colpisce molto a livello visivo anche se formato da un padrão di azulejos molto semplice, come per esempio una scacchiera a due colori. ${ }^{18}$

Partiendo de esta obra, realizada de la segunda mitad del $X X$, el resto de la colección recoge ejemplos más actuales, del 2000 en adelante, para que sean ejemplos más cercanos en tiempo, pero que, al igual que Nery, sus autores tengan un claro interés hacia las formas geométricas, ya sea en la exploración de las formas, en la búsqueda de los patrones, en la investigación sobre el relieve, etc. 


\section{Desde los sistemas geométricos simples a su complejidad caleidoscópica}

Bien es sabido que la geometría, refiriéndonos únicamente a los dos últimos siglos, tuvo una importancia crucial en el arte de las vanguardias y una intensidad teórica en la Bauhaus que ha seguido inspirando a multitud de artistas. Una exposición interesante sobre este tema la encontramos en La persistencia de la geometría, muestra-exposición de la Fundación "la Caixa" y del Museu d'Art Contemporani de Barcelona (MACBA). En esta exposición, aunque se centre más en escultura, encontramos ideas interesantes que nos hacen entender la importancia de la geometría así como su continuidad, tanto en arte como en diseño. Según esta exposición, además de fuente inagotable de inspiración, "la geometría ejerce una función ordenadora y proporciona la armonía necesaria para enfrentarse a la condición aparentemente irregular e inestable de la realidad"19.

A nosotros nos interesa ver la idea de la geometría desde su multiplicidad de usos y recursos. Así partimos del estudio de las formas geométricas esenciales, como por ejemplo el diseño de Torei, creado por Luca Nichetto en 2014. Podríamos considerar que parte la geometría en su forma más minimalista, con unos colores básicos que ayudan a entender la función ordenadora que mencionábamos.

Otra de las formas usuales, a las que recurren los diseñadores, es el estudio de estas formas simples para crear patrones, que posteriormente se van a repetir en los diseños. La silla Antiboy de la española Patricia Urquiola o el packaging realizado por el estudio mexicano Anagrama, para Capicúa, son dos ejemplos del uso de patrones. "La palabra Capicúa se define como un número simétrico que puede leerse igual de arriba a abajo que de derecha a izquierda (...) Nuestra propuesta de diseño toma esta iniciativa y la refleja visualmente en una serie de patrones y formas simétricas que generan un sentido de orden perfecto y limpieza, con el propósito de combinar un estilo único con la planeación"20.

Otro ejemplo de cómo la modulación puede suponer una buena técnica para los diseñadores es el uso que hace de ello Andreu Carulla, en el plato que realiza para el restaurante Can Roca. Esta genial forma de combinar la estética con la funcionalidad es lo que hace de este diseño una excepcional muestra de maestría. Es tal el grado de ingenio del plato en sí, potenciado por el prestigio del Can $\mathrm{Roca}^{21}$, que puede presentarse como una obra única en cada momento, puesto que es la persona la que amolda el plato a sus necesidades. La profundización en el estudio de los patrones va a conllevar diseños tan impactantes como el que nos presenta Aroa Veiga con The Fractal Orange (otoño-invierno 2014) desde la escuela ESDEMGA. "A partir de la repetición del patrón base en distintos ejes, y mediante superposición de los mismos, se obtiene el diseño fractal que da personalidad a todo la colección presentada" ${ }^{22}$. Vemos cómo la complejidad de los patrones, o la ruptura de éstos, nos hace llegar a expandir la geometría. El Kaleidoscope de André Teoman Studio en Portugal puede llegar a ser un ejemplo magnífico.

Los ejemplos previamente citados muestran una exploración de las formas geométricas. No obstante, también encontramos, al recorrer la colección, que estas formas geométricas pueden ser utilizadas por la experiencia óptica que producen. Así como ya se investigó sobre los aspectos 
ópticos de los colores y las formas, con el op art o con el arte cinético, se aprecia cómo de igual manera estas cuestiones inquietan a los diseñadores. Las distorsiones ópticas generadas normalmente por los colores, o como sucede con el arte cinético con el movimiento, son también utilizadas por diseñadores como Massimo Vignelli o Patricia Urquiola. Es interesante cómo Massimo Vignelli habla de su Cubo Seat, 2008, en vídeo añadido también a la colección (https://www.pinterest.com/pin/4892035 78251119012/) porque el propio Vignelli habla de su concepción de haber realizado esta silla en formato modular, donde cada pieza puede tener varias funciones y pueden moverse y recolocarse, así como el toque visual al crear distintos colores para las distintas partes. De igual manera, Urquiola ha elegido las distintas gradaciones de color para sugerir una apariencia de tridimensionalidad. Es por ésto que la geometría se usa también en este sentido más perspectivo y experiencial. Junto a estos dos diseños pueden considerarse esta indagación en el relieve y la dimensión matérica en otros proyectos como el Exciton XL, diseñado por Giovanni Barbieri en 2012, o la Identidad visual del Departamento de Medio Ambiente del Ayuntamiento de Barcelona, Mario Eskenazi.

Estas son algunas de las líneas que sugerimos que tengan en cuenta a la hora de ver/recorrer la exposición, pero, si bien es cierto, pensamos que hay muchas más como puede ser el mestizaje que se puede contemplar en Mayúscula Brands para Fedrigoni y su Work is love made visible. Otra de las relaciones más interesantes es ver en qué medida los logotipos y diseños corporativos de los festivales de diseño (como los dos de Barcelona que se han puesto de ejemplo) pueden mostrar la esencia del diseño del momento. Se puede apreciar que este tema es muy sugerente y merece la pena disfrutar de él y como colección colectiva que es, participar en él.

\footnotetext{
${ }^{1}$ Correo-e: mariacasasgonzalez@gmail.com

${ }^{2}$ Citado de este modo en GARCÍA-GARRIDO, Sebastián, Diseñar para una era humanista. Innovación transversal entre Arte, Diseño y Artesanado, IED Madrid 2015.
}

3 Utilizaré el término que prefieren utilizar Desvallées, A./Mairesse, F. (eds.), Conceptos Claves de Museología, Armand Colin \& ICOM, Paris 2010, pp. 38-39. http://icom.museum/fileadmin/user_upload/pdf/ Key_Concepts_of_Museology/Museologie_Espagnol_BD.pdf (25.06.2015)

${ }^{4}$ Colorado Castellary, Arturo, "Perspectivas de la cultura digital", Zer, vol. 15, núm. 28, 2010, p. 104.

${ }^{5}$ HALL, Catherine/ZARRO, Michael, en Social Curation on the Website Pinterest.com, ASIST 2012, October 28-31, 2012, p. 2. https://www.asis.org/asist 2012/proceedings/Submissions/189.pdf (24.06.2015)

6 Alonso Fernández, Luis/García Fernández, Isabel, Diseño de exposiciones. Concepto, instalación y montaje, Alianza Forma, Madrid 2010. http://fido.palermo.edu/servicios_dyc/blog/docentes/trabajos/14058_4 7095.pdf (23.06.2015)

7 HALL, Catherine/ZARRO, Michael, op. cit. p. 2, https://www.asis.org/asist 2012/proceedings/Submissions/189.pdf (24.06.2015)

8 Ibidem.

${ }^{9}$ Al igual que en Pinterest (https://business.pinterest.com/es/rich-pins) en twitter se han desarrollado iniciativas como Twitter Cards (https://dev.twitter.com/cards/overview), estas iniciativas están teniendo más éxito en el ámbito de los negocios, pero podría ser igual de provechoso a la hora de realizar ciertas investigaciones.

${ }^{10}$ Entendemos hipermedia como el soporte informático que permite el desarrollo del hipertexto, como lo explica Colorado Castellary, Arturo, op. cit. p. 104.

${ }^{11}$ Desvallées, A./Mairesse F. (eds.), op. cit. p. 39. 
12 Martín Prada, Juan, "La creatividad de la multitud conectada y el sentido del arte en el contexto de la Web 2.0", Estudios visuales, n. 5, 2008, p. 77, www.estudiosvisuales.net/revista/pdf/num5/prada_20.pdf (19.06.2015)

${ }^{13}$ García Garrido, Sebastián, "Editorial. Identidad y proyecto de la revista", en i+Diseño, vol. 01, Málaga marzo-2009, pp. 3-6. http://www.diseno.uma.es/i_diseno/PDF_I_DISENO/i_diseno_num_1.pdf (20.05.2015)

${ }^{14}$ García Garrido, Sebastián, Identidad del Diseño de la Cultura Clásica Contemporánea ante el humanismo en la era de las redes interpersonales. Sociedad Erasmiana de Málaga, 2014, p. 7.

${ }^{15}$ García Garrido, Sebastián, Ibidem, p. 40.

${ }^{16}$ Recomiendo para una lectura profunda, de la evolución de los azulejos en Portugal, los apuntes del profesor Nico Stringa "Gli Azulejos Portoghesi. Tra arte e decorazione nel XIX e XX secolo". http://dspace.unive.it/bitstream/handle/10579/4929/823237-1173645.pdf (28.06.2015)

17 Stringa, Nico, op. cit., p. 67.

18 Stringa, Nico, op. cit.

${ }^{19}$ Bisbe, Nimfa, Catálogo de la exposición La persistencia de la geometría, Obra Social "la Caixa" 2012, p. 7. http://www.publicacionestecnicas.com/geometria/files/Persistencia_de_la_geometria/descargas/ Persistencia_de_la_Geometria.pdf (30.06.2015)

${ }^{20}$ Página web de Anagrama: http://www.anagrama.com/portafolio/197-capic\%C3\%BAa

${ }^{21}$ Mejor restaurante del mundo 2015 por la revista inglesa Restaurant. http://elpais.com/elpais/2015/06/01/ estilo/1433191275_703493.htm

22 Dopico, Lola "The Fractal Orange" en DEBUT2014 ESDEMGA. Estudos Superiores en Deseño Téxtil e Moda de Galiza. Universidade de Vigo, Pontevedra 2014, p. 23.

\section{BIBLIOGRAFÍA}

ALONSO FERNÁNDEZ, Luis/GARCÍA GERNÁNDEZ, Isabel, Diseño de exposiciones. Concepto, instalación y montaje, Alianza forma, 2010. http://fido.palermo.edu/servicios_dyc/blog/docentes/trabajos/14058_4 7095.pdf

BISBE, Nimfam, Catálogo de la exposición La persistencia de la geometría, Obra Social "la Caixa" 2012 en http://www.publicacionestecnicas.com/geometria/files/Persistencia_de_la_geometria/descargas

/Persistencia_de_la_Geometria.pdf

COLORADO CASTELLARY, Arturo, "Perspectivas de la cultura digital", Zer, vol. 15, núm. 28, 2010.

DESVAlLÉES, A./MAIRESSE, F. (eds.), Conceptos Claves de Museología, Armand Colin \& ICOM, Paris 2010. http://icom.museum/fileadmin/user_upload/pdf/Key_Concepts_of_Museology/Mu seologie_Espagnol_BD.pdf

DOPICO, Lola, DEBUT2014 ESDEMGA. Estudos Superiores en Deseño Téxtil e Moda de Galiza. Universidade de Vigo, Pontevedra 2014.

GARCÍA GARRIDO, Sebastián

—-Editorial. Identidad y proyecto de la revista", en i+Diseño. Revista Internacional de Innovación, Investigación y desarrollo en Diseño, vol. 01, Málaga, marzo-2009.

http://www.diseno.uma.es/i_diseno/PDF_I_DISENO/i_diseno_num_1.pdf

- Identidad del Diseño de la Cultura Clásica Contemporánea ante el humanismo en la era de las redes interpersonales. Sociedad Erasmiana de Málaga, 2014.

HALL, Catherine/ZARRO, Michael, "Social Curation on the Website Pinterest.com", ASIST 2012, October 28-31, 2012, https://www.asis.org/asist 2012/proceedings/Submissions/189.pdf

STRINGA, Nico, "Gli Azulejos Portoghesi, Tra arte e decorazione nel XIX e XX secolo" http://dspace.unive.it/bitstream/handle/10579/4929/823237-1173645.pdf

MARTÍN PRADA, Juan, "La creatividad de la multitud conectada y el sentido del arte en el contexto de la Web 2.0", Estudios visuales, núm. 5, 2008. www.estudiosvisuales.net/revista/pdf/num5/prada_20.pdf 
OTROS RECURSOS

http://www.anagrama.com/

https://twitter.com/

https://es.pinterest.com/

Revista internacional de investigación, innovación y desarrollo en Diseño • ISSN 1889-433 x

Grupo de investigación Lenguaje Visual y Diseño Aplicado • Plan Andaluz de Investigación • E. Politécnica S. • Universidad de Málaga 